\title{
Double-Unit Superomedio-Central (DUS) Pedicle Inverted-T Reduction Mammaplasty in Gigantomastia: A 7-year Single- Center Retrospective Study
}

\author{
A. Wolter ${ }^{1,2}$ (I) S. Fertsch ${ }^{1}$ B. Munder ${ }^{1}$ - P. Stambera ${ }^{1}$ - T. Schulz ${ }^{1}$. \\ M. Hagouan ${ }^{1}$ - D. Janku' ${ }^{1}$ K. Staemmler ${ }^{1}$ - L. Grueter ${ }^{1}$ - N. Abu-Abdallah ${ }^{1}$. \\ K. Becker ${ }^{1}$ B. Aufmesser ${ }^{1}$. J. Kornetka ${ }^{1}$ - C. Andree ${ }^{1}$
}

Received: 7 March 2021 / Accepted: 9 May 2021/Published online: 18 June 2021

(C) The Author(s) 2021

\begin{abstract}
Introduction Reduction mammaplasty in patients with gigantomastia is challenging. The Double-Unit technique with a Superomedio-Central pedicle and inverted- $T$ incision is the standard technique for reduction mammaplasty in our clinic. The aim of this study was to review our approach in cases with gigantomastia in comparison with the current literature.

Patients and Methods From 01/2011 to 12/2017, we performed 831 reduction mammaplasties in 630 patients. The Double-Unit Superomedio-Central (DUS) pedicle and inverted- $T$ incision was implemented as a standard procedure for gigantomastia. Patient demographics and the outcome parameters complication rate, patient satisfaction with the aesthetic result, nipple sensibility, and surgical revision rate were obtained and retrospectively analyzed.

Results In 37 patients, 55 reduction mammaplasties were performed with more than $1000 \mathrm{~g}$ per breast. Mean resection weight was $1311 \mathrm{~g}$ on right side and $1289 \mathrm{~g}$ on left side. Mean age was 52.5 years, mean body mass index was $32.8 \mathrm{~kg} / \mathrm{m}^{2}$, mean sternal-notch-to-nipple distance was 38.3 $\mathrm{cm}$. A free NAC graft was necessary in four breasts.
\end{abstract}

Supplementary Information The online version contains supplementary material available at https://doi.org/10.1007/s00266021-02351-y.

\footnotetext{
A. Wolter

a_wolter@gmx.de

1 Department of Plastic and Aesthetic Surgery, Interdisciplinary Breast Center, Sana Kliniken Duesseldorf GmbH, Graeulinger Strasse 120, 40625 Duesseldorf, Germany

2 Faculty of Health, University of Witten-Herdecke (UWH), Alfred-Herrhausen-Strasse 50, 58448 Witten, Germany
}

Overall complication rate was $14.5 \%$; secondary surgical revision rate was $12.7 \%$. $91 \%$ of the patients were "very satisfied" and "satisfied" with the aesthetic result. Nipple sensibility was rated "high" and "medium" in $83 \%$.

Conclusion The Double-Unit technique with a Superomedio-Central pedicle and inverted- $T$ incision is very effective to achieve volume reduction and aesthetically pleasing reproducible results with a low complication rate in cases with gigantomastia.

Level of Evidence Level of Evidence This journal requires that authors assign a level of evidence to each article. For a full description of these Evidence-Based Medicine ratings, please refer to the Table of Contents or the online Instructions to Authors www.springer.com/00266.

Keywords Gigantomastia · Macromastia - Severe mammahypertrophy $\cdot$ Reduction mammaplasty $\cdot$ Breast reduction $\cdot$ Superomedial pedicle

\section{Introduction}

"Gigantomastia" describes a rare extreme hypertrophy of the female breast. Although there is no universally accepted definition, many authors cite gigantomastia as breast enlargement that requires a reduction mammaplasty of $>1000 \mathrm{~g}$ per breast [1-4]. Various procedures have been described for reduction mammaplasty with specific skin incisions, patterns of breast parenchymal resection and retained blood supply to the remaining breast tissue and nipple-areolar complex (NAC) [5, 6]. To date, only a limited number of publications can be found in literature addressing the challenging condition of gigantomastia [2-4, 7-12]. 
A very important issue in breast reduction surgery is the preservation of the vascularity of tissues as well as sensibility, especially of the NAC. Various pedicle techniques have been described in breast reduction surgery [13]. The superomedial pedicle is commonly used in Europe [9, 14], whereas the inferior or central pedicle is favored in the USA [2]. In case of an extremely elongated sternal-notchNAC (SN-NAC) distance of $>40 \mathrm{~cm}$ or more, many authors recommend a free NAC grafting [15, 16]. The superomedial dermal pedicle for NAC transposition was first described by Orlando and Guthrie for use in reduction mammaplasty and mastopexy [17].

Elizabeth Hall-Findlay described in 1999 a vertical scar medial (or superomedial) pedicled breast reduction technique as a modification to the standard Lejour [18] vertical reduction mammaplasty, and this technique has grown rapidly in popularity [19-21]. There is no difficulty in insetting the NAC to its new site, and this technique is safer than the superior pedicle vertical technique in terms of NAC circulation. Some modifications of the "Hall-Findlay Technique" have already been published [22-24] but none to date addressing gigantomastia cases. However, the HallFindlay technique is not without problems, like bottoming out and dog ears in the inframammary fold (IMF). In her book, E. Hall-Findlay describes in 2011 the necessity of an inverted- $T$ scar regarding two patient examples: one case after massive weight loss and one with gigantomastia [25]. Especially in gigantomastia cases, NAC ischemia is a threatening complication. The two novelties presented in our study are an horizontal incision at the IMF and the preservation of the fibrous horizontal septum (described by Wueringer et al. [26]) with its containing vessels included in the central pedicle part additionally to the superomedial pedicle (Double-Unit Superomedio-Central (DUS) Pedicle). To date, there is no relevant publication addressing this technique in gigantomastia cases. The purpose of this study is to show a modification of Hall-Findlay's technique with a Double-Unit Superomedio-Central pedicled inverted- $T$-scar reduction mammaplasty in gigantomastia and a retrospective analysis regarding complications, patient satisfaction, and NAC sensibility.

\section{Patients and Method}

The records of 630 patients who underwent 831 reduction mammaplasties under general anesthesia from January 2011 to December 2017 were retrospectively reviewed. A resection weight of more than $1000 \mathrm{~g}$ per breast corresponding to the definition of gigantomastia was defined as inclusion criterion. The data collected included patient demographics (age, body mass index (BMI kg/m²), SNNAC distance, operation time, hospital stay, and amount of resected breast tissue (Table 1). Outcome parameters such as complication rate, patient satisfaction with the aesthetic result, nipple sensibility, and the secondary revision rate were recorded and evaluated (Tables 2 and 3). All patients were photographed preoperatively, 6 months, and 1 up to 4 years postoperatively in standard perspectives.

\section{Markings}

Preoperative markings were made while the patient was standing according to the standard reduction mammaplasty in our clinic (Figs.1, 2 and 3 and Video File 1).

\section{Surgical Technique}

Surgery was performed under general anesthesia with the patient in a supine position (see also Fig. 4 and Video File 2). After a single-shot antibiosis, the NAC was marked with a "cookie cutter" (38-42 mm). We used a temporary tourniquet of the breast to facilitate the deepithelialisation process. The NAC-bearing pedicle was then de-epithelialized with scissors or scalpel with special regard to the preservation of the subdermal venous plexus. The Superomedio-Central pedicle was prepared down to the pectoralis fascia under preservation of the fibrous horizontal septum, described by Wueringer et al. [26]. The horizontal septum is a thin layer of connective tissue that arises from the pectoralis fascia at the level of the fifth rib and reaches the NAC. It divides the breast into cranial and caudal parts (Figs. 5, 6 and Figs. 4A + B). In gigantomastia, the vascular anatomy of the breast remains but the breast is more ptotic with an increased SN-NAC distance and broad base. The vascular supply to NAC relies mainly on perforating arterial branches from the internal mammary artery, the lateral thoracic artery at the level of the 2nd and 3rd

Table 1 Patient demographics (36 patients, breasts: $n=55$ )

\begin{tabular}{ll}
\hline $\begin{array}{l}\text { Overall collective } \\
\text { Patients }\end{array}$ & $n=36,55$ breast reductions \\
\hline Age (years) & $52.5(18-76)$ \\
BMI $\left(\mathrm{kg} / \mathrm{m}^{2}\right)$ & $32.8(22-40.5)$ \\
Sternal notch-NAC distance $(\mathrm{cm})$ & $38.3(27-56)$ \\
Operation time (min) & $164(76-288)$ \\
Hospital stay (days) & $4.9(2-9)$ \\
Resection weight right side $(\mathrm{g})$ & $1311(1000-4200)$ \\
Resection weight left side $(\mathrm{g})$ & $1289(1005-4600)$ \\
Free NAC grafting & 4 breasts $(7.2 \%)$ \\
\hline
\end{tabular}

(BMI body mass index $\mathrm{kg} / \mathrm{m}^{2}, N A C$ nipple-areolar complex) 
Table 2 Outcome parameters-Complications and surgical revisions

\begin{tabular}{ll}
\hline Outcome parameter & $\begin{array}{l}\text { Overall collective } \\
n=55 \text { breast reductions }\end{array}$ \\
\hline Overall Complications & $8(14.5 \%)$ \\
Minor & $6(10.9 \%)$ \\
NAC epidermiolysis & $2(3.6 \%)$ \\
Seroma & $1(1.8 \%)$ \\
Local wound infection & $1(1.8 \%)$ \\
Delayed wound healing $(T$ point $)$ & $2(3.6 \%)$ \\
Major & $2(3.6 \%)$ \\
Total NAC necrosis & $1(1.8 \%)$ \\
Acute hematoma with revision & $1(1.8 \%)$ \\
Secondary revisions & $7(12.7 \%)$ \\
Contour revisions & $3(5.5 \%)$ \\
Scar revisions & $2(3.6 \%)$ \\
NAC revisions & $2(3.6 \%)$ \\
\hline
\end{tabular}

(NAC nipple-areolar complex)

Table 3 Outcome parameters-Patient survey evaluation

\begin{tabular}{ll}
\hline & $\begin{array}{l}\text { Patient survey evaluation } \\
n=33 / 36(92 \%) \text { patients }\end{array}$ \\
\hline $\begin{array}{l}\text { Patient satisfaction } \\
1=\text { Very satisfied } \\
2=\text { Satisfied }\end{array}$ & $21(64 \%)$ \\
$3=$ Less satisfied & $9(27 \%)$ \\
$4=$ Not satisfied & $2(6 \%)$ \\
NAC sensibility & $1(3 \%)$ \\
$1=$ High & $n=42$ (free NAC grafts excluded) \\
$2=$ Medium & $21(50 \%)$ \\
$3=$ Low & $14(33 \%)$ \\
$4=$ No sensation & $4(10 \%)$ \\
\hline
\end{tabular}

(NAC nipple-areolar complex)

intercostal artery, and the anterior intercostal artery at the level of the mid fourth and mid fifth intercostal space (Figs. 5, 6 and Fig. 4B). The fibrous horizontal septum includes the perforators from the anterior intercostal artery emerging from the pectoralis major muscle at the level of the fourth and fifth intercostal space. Our technique combines the superomedial pedicle and the central horizontal Wueringer's septal branches (Double-Unit SuperomedioCentral (DUS) Pedicle).

Undermining of the pedicle should be avoided to preserve the vascularity and nerve insertions to ensure a Double-Unit NAC-bearing pedicle consisting of a superomedial and central part. Surgical "en bloc" excision of skin, fat and gland around the pedicle with a $C$-shaped pattern (as described by Hall-Findlay [20]) was performed

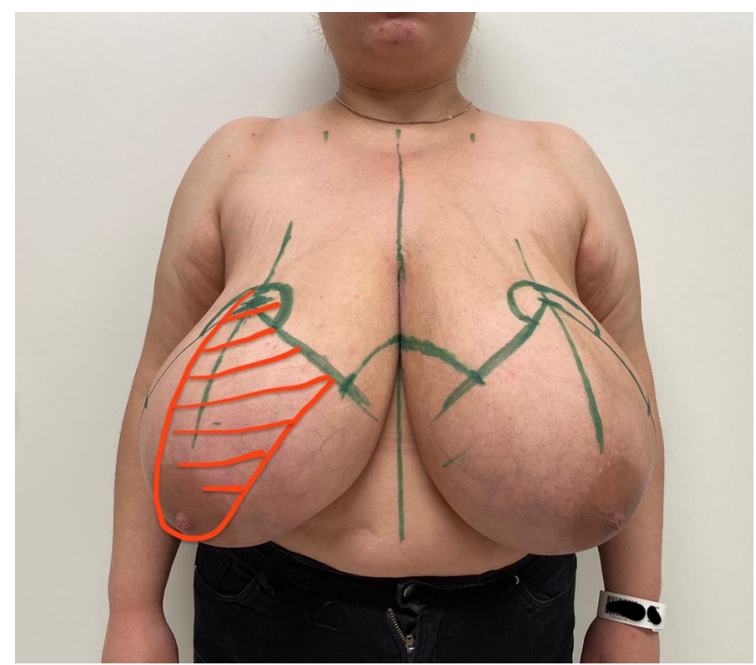

Fig. 1 Patient example with Pedicle Marking (red color) of the Double-Unit Superomedio-Central (DUS) Pedicled Inverted-T Reduction Mammaplasty (green color)

as outlined by skin markings (Figs. 1, 2 and 3). The resection was stopped when the inferior border of the pectoralis major muscle fascia was reached. Resection was then continued to the lateral extension and inferomedial portion of the breast; in some cases with a moderate trimming in the lateral portion of the new NAC area and in individual cases to decrease the volume of a bulky lateral breast pillar. The NAC was then tension-free rotated for inset to its new position and temporarily stapled (Fig. 4C). Symmetry was then checked at the upright sitting patient. After elevation of blood pressure by the anesthesiologists to a systolic minimum of $130 \mathrm{mmHg}$, we irrigated the wounds with warm saline solution and performed a meticulous coagulation. A 12-mm single drain was placed for each breast laterally. Closure was commenced laterally to take up the excess skin and reduce tension at the $T$ junction. The medial and lateral breast pillars were sutured in two planes, respectively deep in the parenchyma with 2-0 PDS single knots to avoid a bottoming out and to preserve upper pole projection. The anchor suture in the $T$ junction point was performed with a resorbable 2-0 Monocryl single knot. Skin closure was performed with resorbable 3-0 Monocryl single knots and a running suture intracutaneously in the IMF and vertically. The NAC's skin closure was performed with a 4-0 resorbable Monocryl double running suture intracutaneously (Fig. 4D).

Only in cases with a sternal-notch-NAC distance $>45$ $\mathrm{cm}$, we adopted the free NAC graft technique and used a pseudo-pedicle prepared as described before as NAC recipient site. In all cases, the resected breast glandular tissue was analysed histopathologically. Drains were removed when secretion decreased below $30 \mathrm{ml}$ in 24 hours. Early mobilization and anticoagulation with low- 
Fig. 2 Patient example 1 with DUS-Pedicle marking. 37-yearold patient with cup size 90 $\mathrm{G} / \mathrm{H}, \mathrm{SN}-\mathrm{NAC}$ distance $35 \mathrm{~cm}$ right side and $34 \mathrm{~cm}$ left side, ptosis grade III by Regnault, BMI $30.5 \mathrm{~kg} / \mathrm{m}^{2}$. Preoperative status (above), preoperative markings (middle), and 12 months postoperative (below) after Double-Unit SuperomedioCentral (DUS) Pedicled Inverted- $T$ Reduction Mammaplasty, form stable breast shape and good upper pole projection. Resection weight right side $1309 \mathrm{~g}$ and left side 1185 g (BMI: body mass index $\mathrm{kg} / \mathrm{m}^{2}$; $\mathrm{SN}$ : sternal notch, NAC: sternal notch-nippleareolar complex)

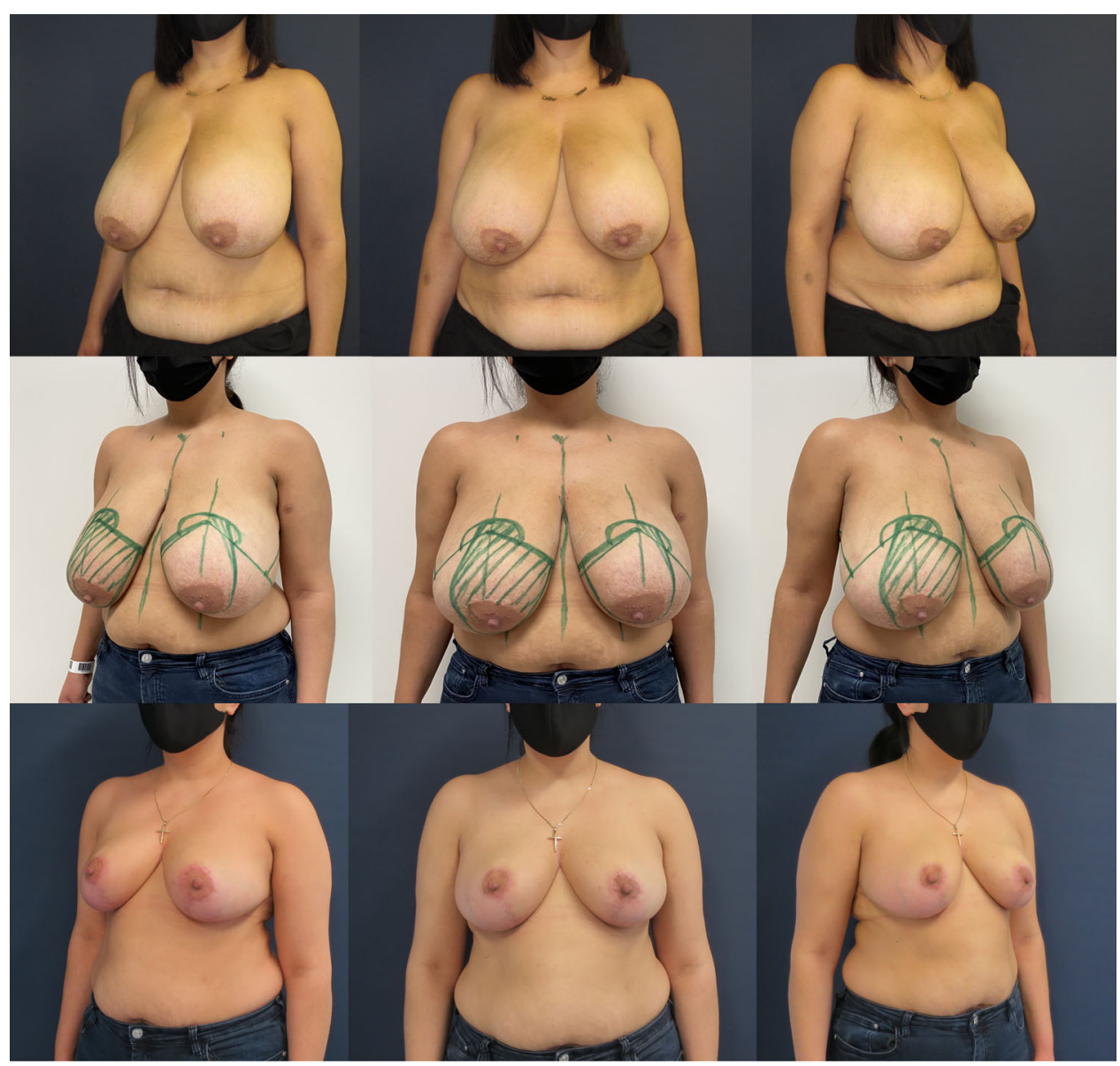

dose heparin were prescribed directly after surgery. Wound dressing was completed by a right fitting compression bra applied immediately in the operating room. All patients were advised to wear this compression bra and to avoid excessive sport and exercises for at least 6 weeks.

To evaluate our results qualitatively, we recorded the complication and secondary revision rate (Table 2). Moreover, a patient satisfaction survey concerning the aesthetic result and a subjective assessment of nipple sensibility were performed as follows (Table 3). Patient satisfaction could be rated as "very satisfied" (1), "satisfied" (2), "less satisfied" (3) and "not satisfied" (4). Nipple sensibility was subjectively evaluated per breast side as "high" (1;1st degree), "medium" (2; 2nd degree), "low" (3; 3rd degree) and "no sensation" (4; 4th degree).

Patients presented to our outpatient department for follow-up at 2 weeks, 6 months, 1 year up to 4 years after surgery or were questioned by telephone interview. The collected data were then transferred into Excel.

In our institution we have a very constant team of six operating plastic surgeons (head of department, five attendings, all German Board, one additionally European Board (EBOPRAS) certified, and six residents) to ensure uniformity of technique and follow-up observation. The surgical team usually consists of one or two attendings and one resident.

\section{Results}

From January 2009 to December 2017, we performed 831 reduction mammaplasties in 630 patients. Fifty-five reduction mammaplasties (7\%) fulfilled the inclusion criteria for gigantomastia with a resection weight of more than $1000 \mathrm{~g}$ per breast. The mean age was 52.5 years (range: 18-76 years), mean distance between sternal notch and NAC was $38.3 \mathrm{~cm}$ (range: $27-56 \mathrm{~cm}$ ), mean body mass index (BMI kg/m ${ }^{2}$ ) was $32.8 \mathrm{~kg} / \mathrm{m}^{2}$ (range: $22-40.5 \mathrm{~kg} /$ $\mathrm{m}^{2}$ ),). The mean operating time lasted $164 \mathrm{~min}$ (range: 76-288 minutes). The mean weight of resected tissue was $1311 \mathrm{~g}$ (range: $1000-4200 \mathrm{~g}$ ) on the right side and $1289 \mathrm{~g}$ (range: $1005-4600 \mathrm{~g}$ ) on the left side. The mean hospital stay was 4.9 days (range: $2-9$ days).

Overall complication was $14.5 \%$ (Table 2). Complications were divided into minor, which could be managed conservatively and major complications, where surgical revision was necessary. Minor complications included seroma, NAC epidermiolysis, local wound infection and 


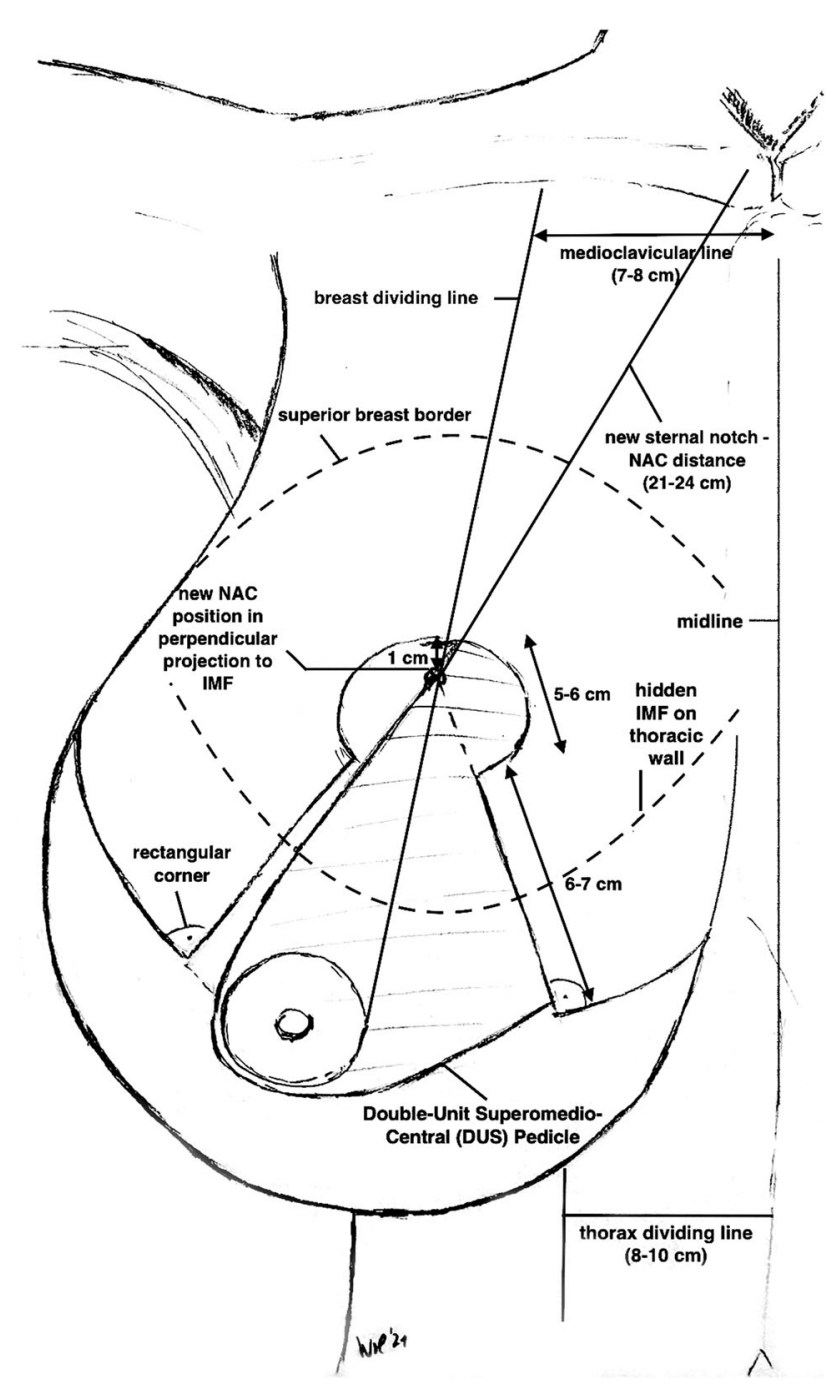

Fig. 3 Illustration of Surgical Markings and measurements of the Double-Unit Superomedio-Central (DUS) Pedicle in a schematic gigantomastic breast (NAC: Nipple-Areola Complex; IMF: Inframammary Fold)

delayed wound healing in the $T$-junction. Major complications included total NAC necrosis and acute hematoma with revision.

There was only one case with an acute hematoma requiring evacuation $(1.8 \%)$ and one full NAC necrosis $(1.8 \%)$ that was reconstructed by skate flap and areolar tattooing. As minor complications there were two NAC epidermiolysises $(3.6 \%)$ that healed by secondary intention, one seroma $(1.8 \%)$ that was evacuated by needle aspiration, one local wound infection $(1.8 \%)$ treated by local antiseptic ointment and antibiotics and two delayed wound healings in the $T$-junction (3.6\%), that healed completely by secondary intention. Secondary surgical revisions for aesthetic improvement (e.g., contour revisions, scar revisions or NAC revisions) were necessary in seven cases $(12.7 \%)$. Flap/pedicle or steatonecrosis did not occur.

Thirty-three patients (92\%) could be interviewed during the follow-up appointments and by telephone survey. The mean follow-up time was 24 months (12-48 months). The patient survey revealed a high satisfaction rate with the aesthetic result (Table 3). 21 patients (64\%) rated the results as "very satisfied" (1), 9 patients (35\%) as "satisfied" (2), 2 patients (6\%) were "less satisfied" (3), one patient (3\%) was „not satisfied“ (4). Nipple sensibility was rated subjectively by the patients in 21 NACs (50\%) as "high" (1) and in 14 NACs (33\%) as "medium" (2), in 4 NACs (10\%) as „low“ (3) and in three NACs (7\%) with „no sensation“ (4) (one total NAC necrosis). Cases with free NAC grafting were excluded in the sensibility analysis. No malignant or pathological findings were seen in the histopathological analysis.

\section{Discussion}

Over the last decades, breast reduction techniques became numerous. Gigantomastia breast reduction, in particular, is still challenging and has a high complication rate. Factors that can negatively affect the outcome of a reduction mammaplasty have already been previously frequently described (e.g., age, BMI kg/m², grade of ptosis, comorbidities, smoking and amount of resection weight) [27, 28]. Due to fact that NAC necrosis and loss of NAC sensation are the most severe complications of reduction mammaplasty, safety is mainly dependent on assuring blood and nerve supply to the NAC. The complication of NAC necrosis in breast reduction and mastopexy has been reported up to $7.3 \%$ [8]. Due to the severely increased SNNAC distance in gigantomastic breasts, the vascular safety of the NAC remains a primary concern. In normal-sized breasts reduction mammaplasties the inferior, superior, medial or lateral pedicle provides adequate blood supply to the NAC, but might not include sufficient arterial flow and venous output to the NAC in cases of gigantomastia. Van Deventer et al. analysed the arterial breast blood supply through a cadaver research project and concluded that even though the main sources are constant (internal/lateral thoracic, anterior intercostal and acromiothoracic artery), partial or complete absence of branches can occur. Due to this unpredictable anatomy and blood supply of the NAC and to reduce the risk of potential NAC loss, they recommended to use a technique including branches from more than one source [29]. Palmer and Taylor analysed the vascular territories of the breast and found the internal thoracic artery to be the dominant blood supply in 70 percent of patients [30]. Furthermore, the only vessel to contribute at least one perforator to the NAC in 100 percent 
Fig. 4 Illustration of Surgical Technique. A, B Double-Unit Superomedio-Central (DUS) Pedicle Inverted-T Reduction Mammaplasty with illustration of vascular supply. C Cranial rotation of DUS-Pedicle and inset of NAC in new position. D Skin closure and stitch-out laterally to vulnerable tripod zone. (NAC: nipple-areola complex)

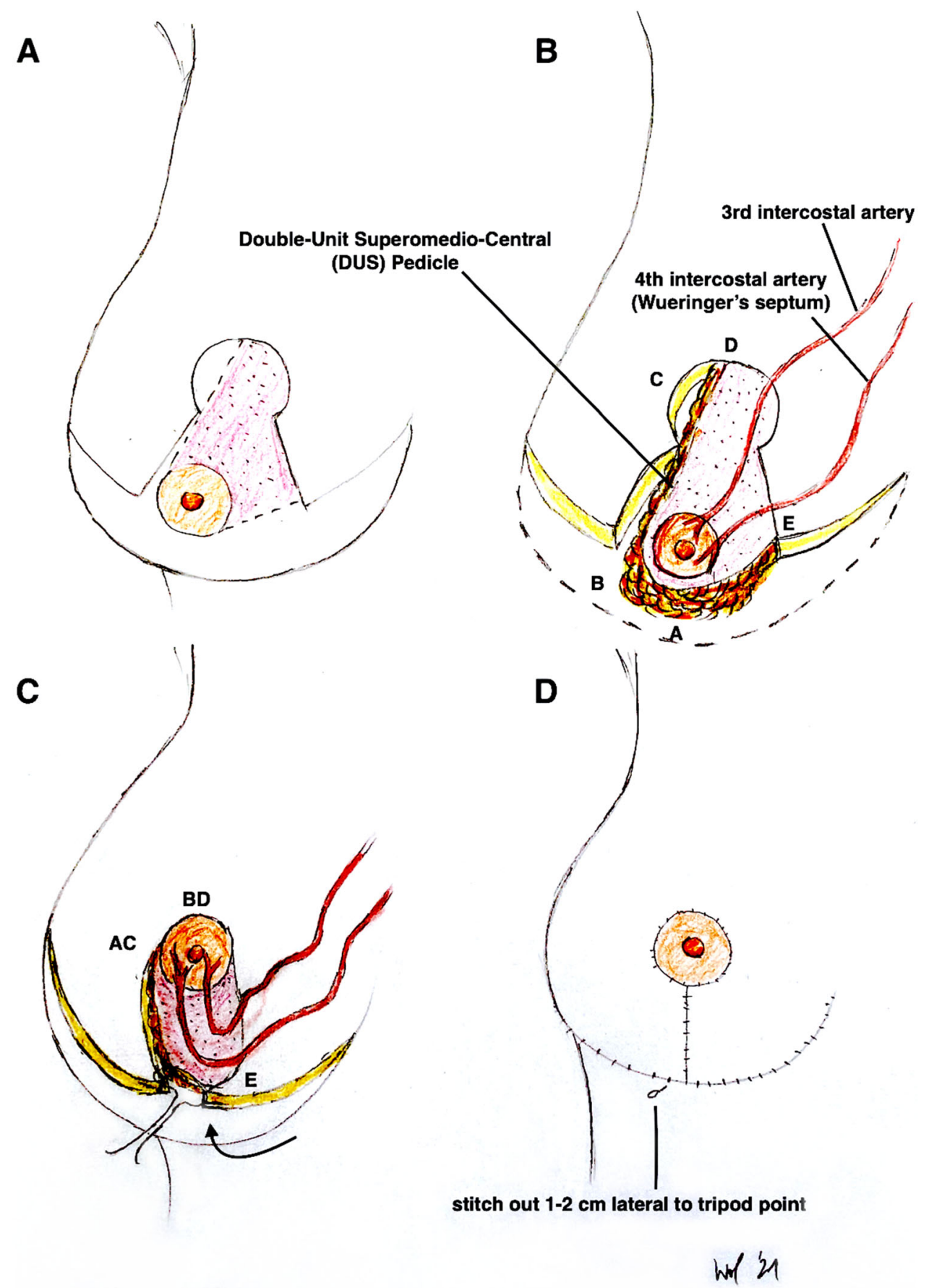

of cases was the internal mammary artery. The superomedial pedicle (which includes these perforators) is therefore a sound anatomical choice. First described by Orlando and Guthrie [17], the superomedial pedicle technique has been demonstrated to be both safe and reliable [3].

In the last decade, the superomedial pedicle with vertical reduction has gained popularity, particularly Elizabeth Hall-Findlay's medial (or superomedial) pedicle vertical reduction mammaplasty technique $[4,20]$. On the other hand, it is not easy to achieve perfect results in gigantomastia cases who have undergone vertical scar breast reduction techniques [31]. Thus, in these cases, the superomedial and inferior pedicle with Wise pattern skin excision is preferred by many authors [9]. Le Roux et al. published an anatomical study concerning the preservation of essential venous drainage networks in breast surgery and claimed the superomedial/medial and inferior pedicles to contain the most extensive venous drainage patterns [24]. Reduction mammaplasty with the inferior pedicle is a well- 
Fig. 5 Anatomical

Illustration of the Double-Unit

Superomedio-Central (DUS)

Pedicle, the vascular supply of the NAC and the Wueringer's horizontal septum [26] in frontal view. (NAC: nippleareola complex)

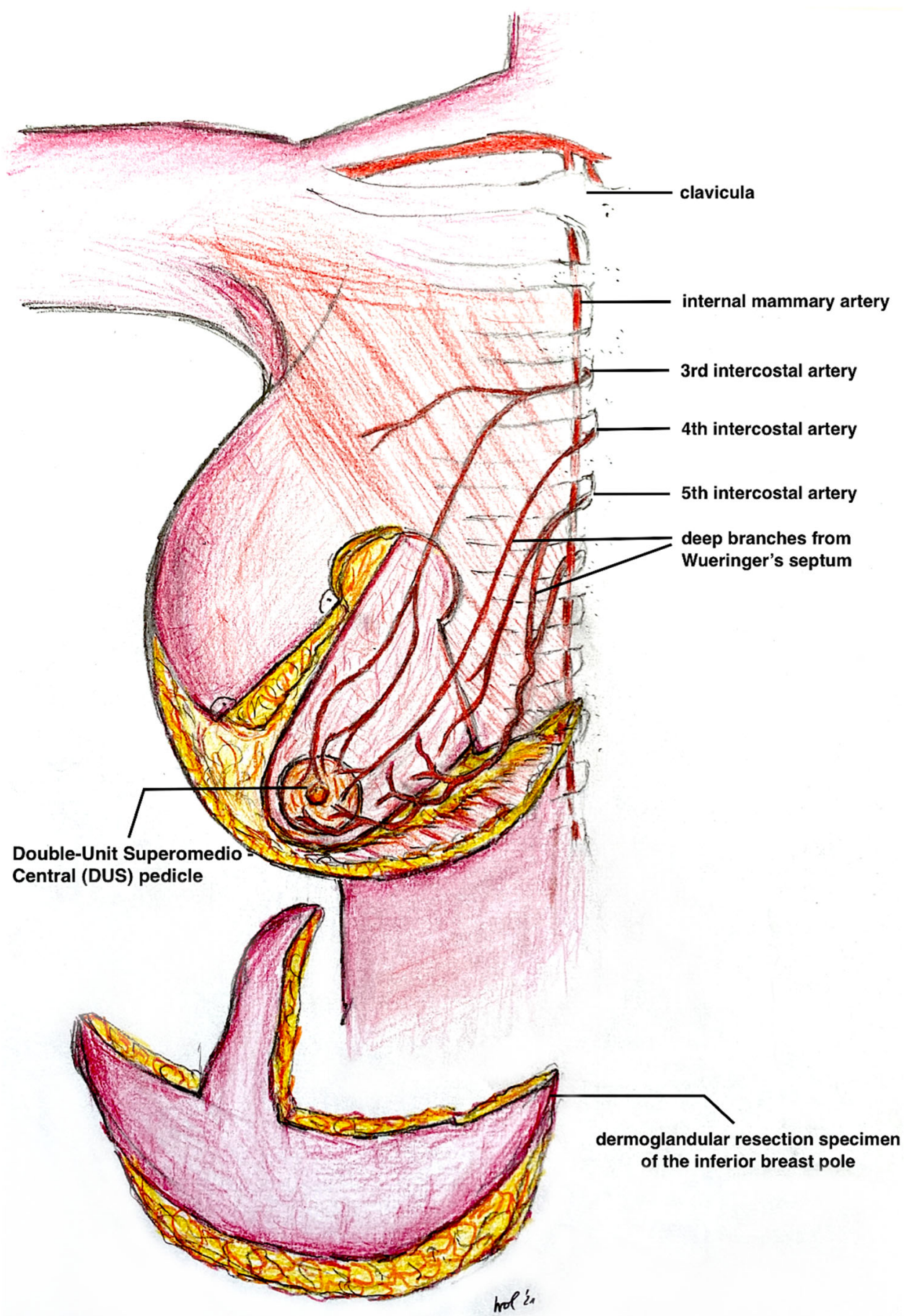

established technique and applicable in a wide range of breast sizes and the complication rate is rather low [32]. Although this is a reliable option for larger resections, development of "bottoming out" is a major criticism of this technique. Especially in gigantomastia cases with extensively impaired skin quality and elasticity, sagging of breast tissue below the inframammary scar is a potential problem. Although the majority of our patients were very satisfied with their outcomes and none complained of a "bottoming-out" deformity, this issue was slightly noticeable in very few patients in our collective (see also patient examples regarding the IMF scar Fig. 7). To avoid this phenomenon even in very massive cases, due to the gravity forces of tissue in the lower pole and the severely impaired skin quality, the NAC should not be placed too high (optimally in perpendicular projection to the IMF) and the vertical pillar limbs should not be planned too short or too long (see also "Markings" Fig. 3). 
Fig. 6 Anatomical illustration of the Double-Unit Superomedio-Central (DUS) Pedicle, the vascular supply of the NAC and the Wueringer's horizontal septum [26] in sagittal view. (NAC: nippleareola complex)

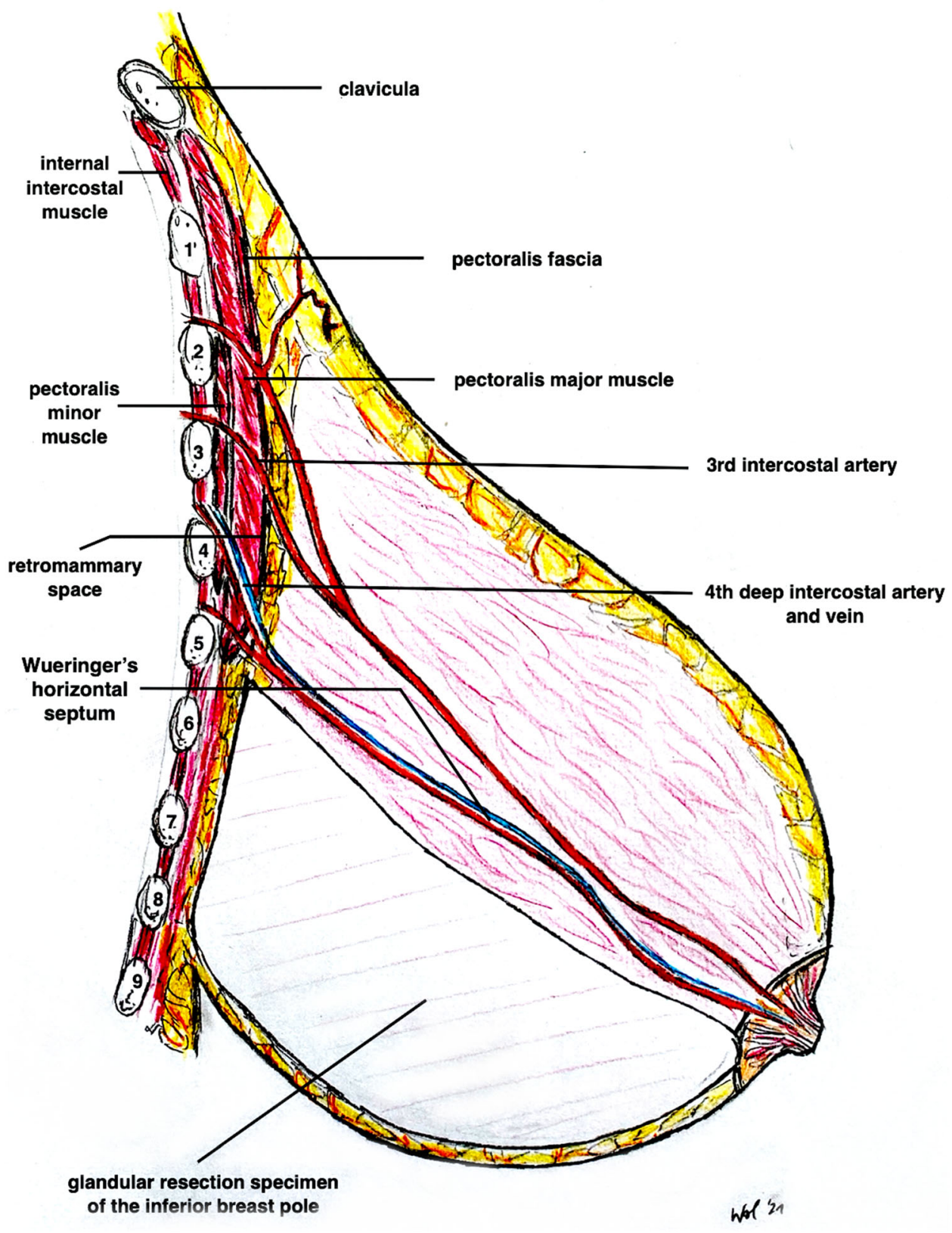

The superomedial pedicle on the other hand is potentially versatile and can be used with various skin reduction techniques. Furthermore the reliability and safety of the superomedial pedicle have been frequently reported $[4,23,33]$. Compared with the inferior pedicle, the superomedial pedicle causes increased breast projection and saves operating time in vertical scar reductions [34].

To modify the Hall-Findlay technique with medial (or superomedial) pedicle, we decided to combine the superomedial pedicle with the central glandular part (including the intercostal perforators from the internal mammary artery and vein). The central pedicle technique was first described by Hester al. in 1985 [35] and later by Wueringer
[36]. Therefore, by combining the superomedial and central pedicle with preservation of Wueringer's septum in this "Double-Unit Superomedio-Central (DUS) Pedicle" technique the risk of NAC loss can potentially be reduced including reliable arterial sources and preserving a sufficient venous NAC drainage. A similar principle was recommended by Bucaria et al. in severe breast ptosis cases [37]. The authors could also show a very low complication rate, especially concerning the risk of a complete NAC loss. The preservation of the fourth and fifth anterior intercostal perforators enhances the vascularization of the breast parenchyma and NAC $[11,26]$. Their preservation can be obtained by avoiding any dissection over the 


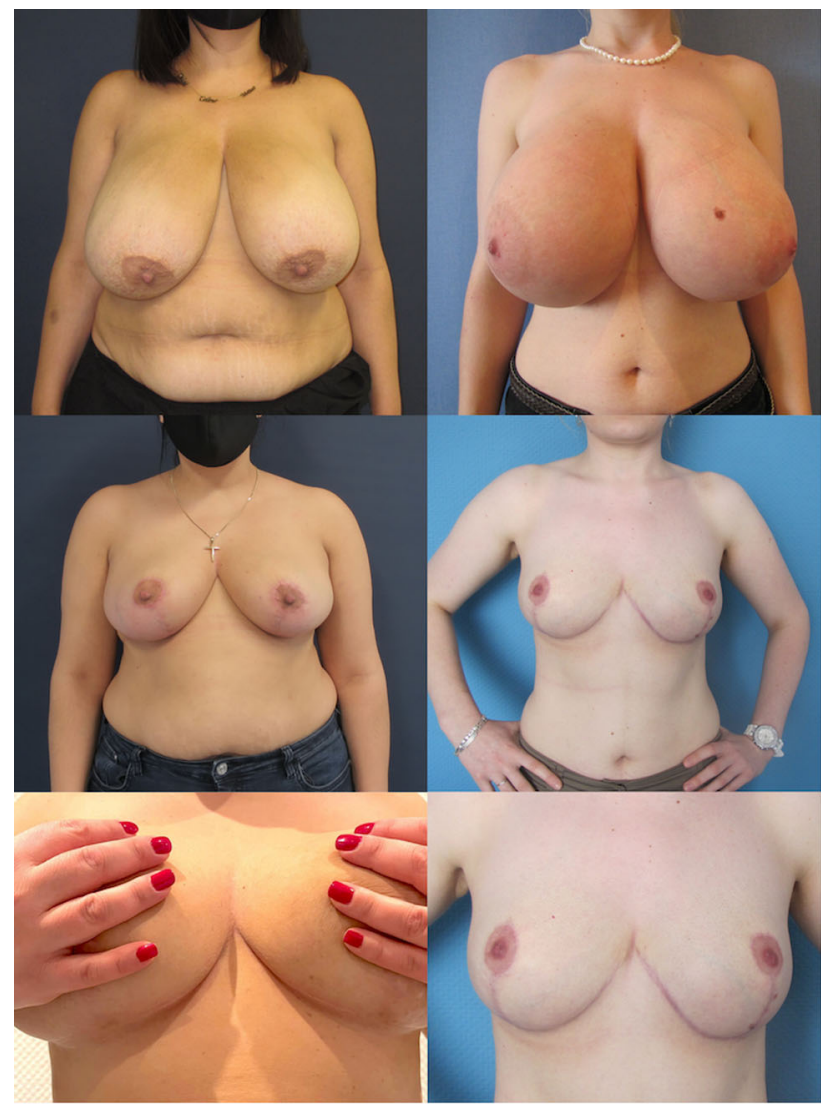

Fig. 7 Patient examples (left side: patient Fig. 2 and right side: Fig. 10) pre- and postoperative with focus on the inframammary (IMF) scar; note: very slight bottoming out in the left case due to advanced age ( 37 years (left side) vs. 23 years (right side)), impaired skin quality and elasticity, more severe grade of breast ptosis and status after breast feeding

pectoralis major muscle, so that Wueringer's [26] septum is preserved. Thus this modified technique can be regarded as a combination of the central mound and the superomedial pedicle techniques (Figs. 1, 2, 3, 4, 5, 6). The broad dermoglandular pedicle together with the oblique design allows for a safe arc of rotation, preventing kinking of the pedicle. In addition to being safe and reliable, the technique has been shown to be relatively quick to perform, saving operating time (mean operation time: $164 \mathrm{~min}$ ).

In the past, the focus has also placed on reducing the length of the scars, respectively by $J$ or $L$ scars $[32,38]$, ending with vertical scar mammaplasty like in Lejour's or Hall-Findlay's technique [10, 18, 20, 21]. Dog-ear deformity at the IMF is always a potential problem in vertical mammaplasty techniques. Expecting that part to settle down in a few months is sometimes in vain. Some authors suggest to place a purse-string suture below the fold [22], but tension can cause wound deshiscences in some cases. In our opinion, patients usually not complain about the inframammary scar as long it is located within the IMF and maximal breast projection area. Furthermore, the shape of the reduced breast should not be compromised to shorten the scars. In gigantomastia, large volumes are usually associated with ptosis, axillary extensions, and hollowness of the upper breast pole. To avoid potential scar, dog ear or volume revisions in the IMF or in the lateral part of the breast, we adopted a wise pattern inverted- $T$ incision. The inframammary scar only exceeded the width of the reduced breast in case of avoiding dog ears in severe lateral bra rolls and remained "hidden" in the IMF or its extension. The length of this scar was reduced whenever possible.

Moreover the multiplanar pillar sutures, placed to fix the gland vertically and in the $T$-junction, are used to decrease tension on the scars and to obtain a long-term breast shape by increasing the breast projection and reducing the risk of a bottoming out in the further course. $T$ junction breakdown is a frequently occurring problem with rates up to $18 \%$ $[4,39]$. In our collective we could reduce this minor complication to two breasts $(3.6 \%)$ by commencement of the key sutures starting laterally so that the lateral skin excess is pushed medially to relieve tension at the tripod point and by placing multiplanar pillar sutures including an anchor suture in the $T$ junction to avoid any stitch-out in this very vulnerable region (Fig. 4D). However, patients need to be aware that delayed healing is not an uncommon problem in gigantomastia. Immediate and late complication rates in gigantomastia can be found in literature up to $36 \%$ [27]. The overall complication rate in this series remained generally low (14.5\%) (in comparison with literature regarding reduction mammaplasty in case of gigantomastia, Table 4), with one acute hematoma requiring evacuation (1.8\%), only one total NAC loss $(1.8 \%)$ in a strong smoking patient and SN-NAC distance of $42 \mathrm{~cm}$ that could be reconstructed by a skate flap and areolar tattooing and two NAC epidermiolysises (3.6\%) that healed by secondary intention. Free NAC grafts were solely performed in extreme $\mathrm{SN}-\mathrm{NAC}$ distances $>45 \mathrm{~cm}$; in our collective in four breasts (see also patient examples Figs. 8, 9, 10, 11). In addition, NAC grafting is associated with loss of NAC sensation, lack of nipple projection, nipple hypopigmentation, and loss of lactation. Thus, it should not be performed on women of childbearing age who plan to breastfeed or women who want to preserve nipple sensation and erection.

Although the Superomedio-Central Pedicle allows to support the NAC's blood supply even in very elongated SN-NAC distances, we recommend that this decision should be supplemented by intraoperatively checking signs of venous congestion concerning the vascular NAC supply. If there is any suspicious NAC perfusion regarding a venous congestion, a free NAC graft should be performed. In 1922, Thorek was the first who described a free-nipple reduction mammaplasty in gigantomastia cases [48]. 


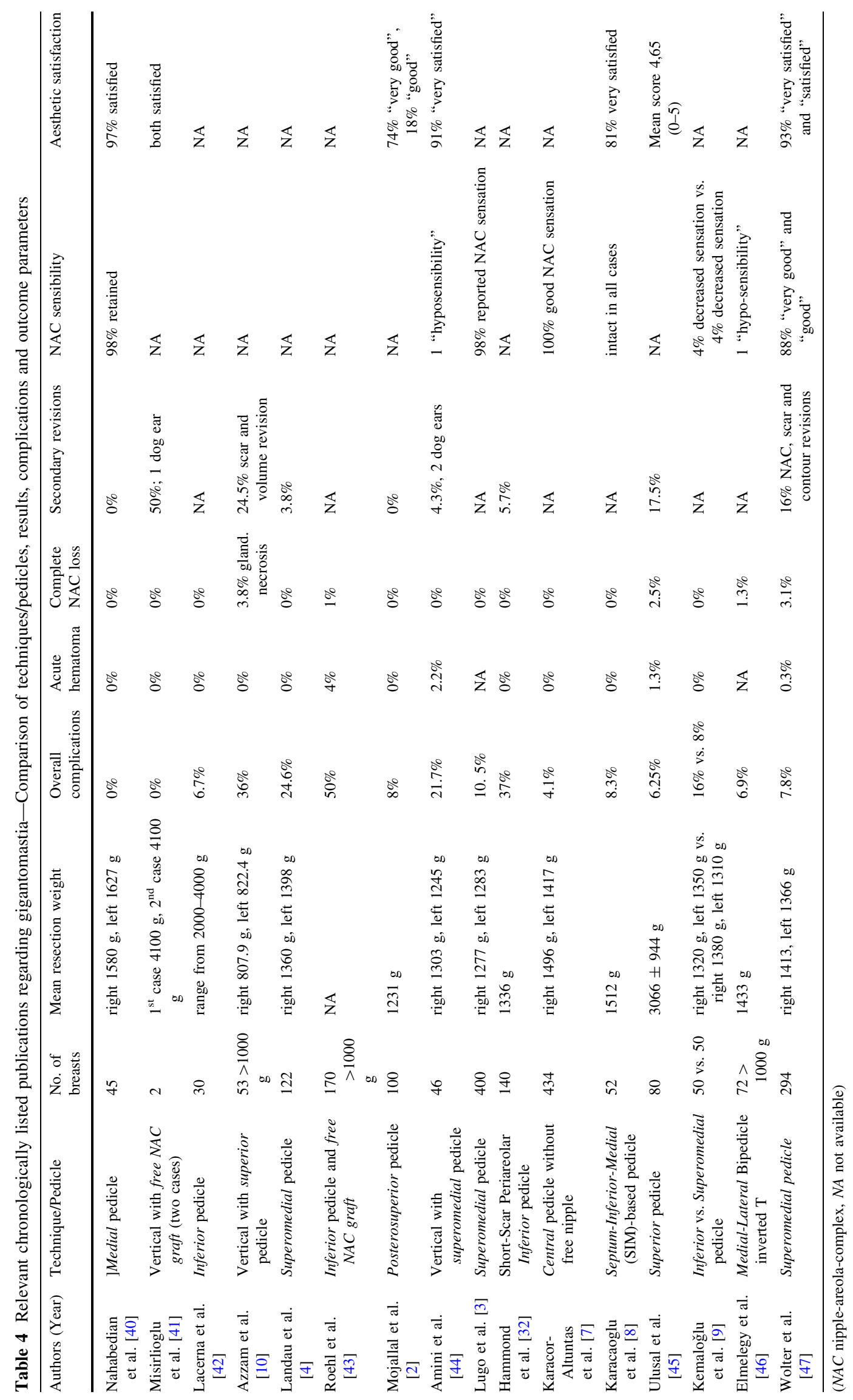


Fig. 8 Patient example 2. 31-year-old patient with cup size $80 \mathrm{M}$, SN-NAC distance 39 $\mathrm{cm}$ right side and $38 \mathrm{~cm}$ left side, ptosis grade III by Regnault, BMI $32 \mathrm{~kg} / \mathrm{m}^{2}$. preoperative markings (middle), and 6 months postoperative (below) after Double-Unit Superomedio-Central (DUS) Pedicled Inverted-T Reduction Mammaplasty, form stable breast shape and good upper pole projection. Resection weight right side $\mathbf{2 1 2 4} \mathbf{g}$ and left side $\mathbf{2 2 4 8}$ g (BMI: body mass index $\mathrm{kg} / \mathrm{m}^{2} ; \mathrm{SN}$ : sternal notch, NAC: sternal notch-nippleareolar complex) Preoperative status (above),
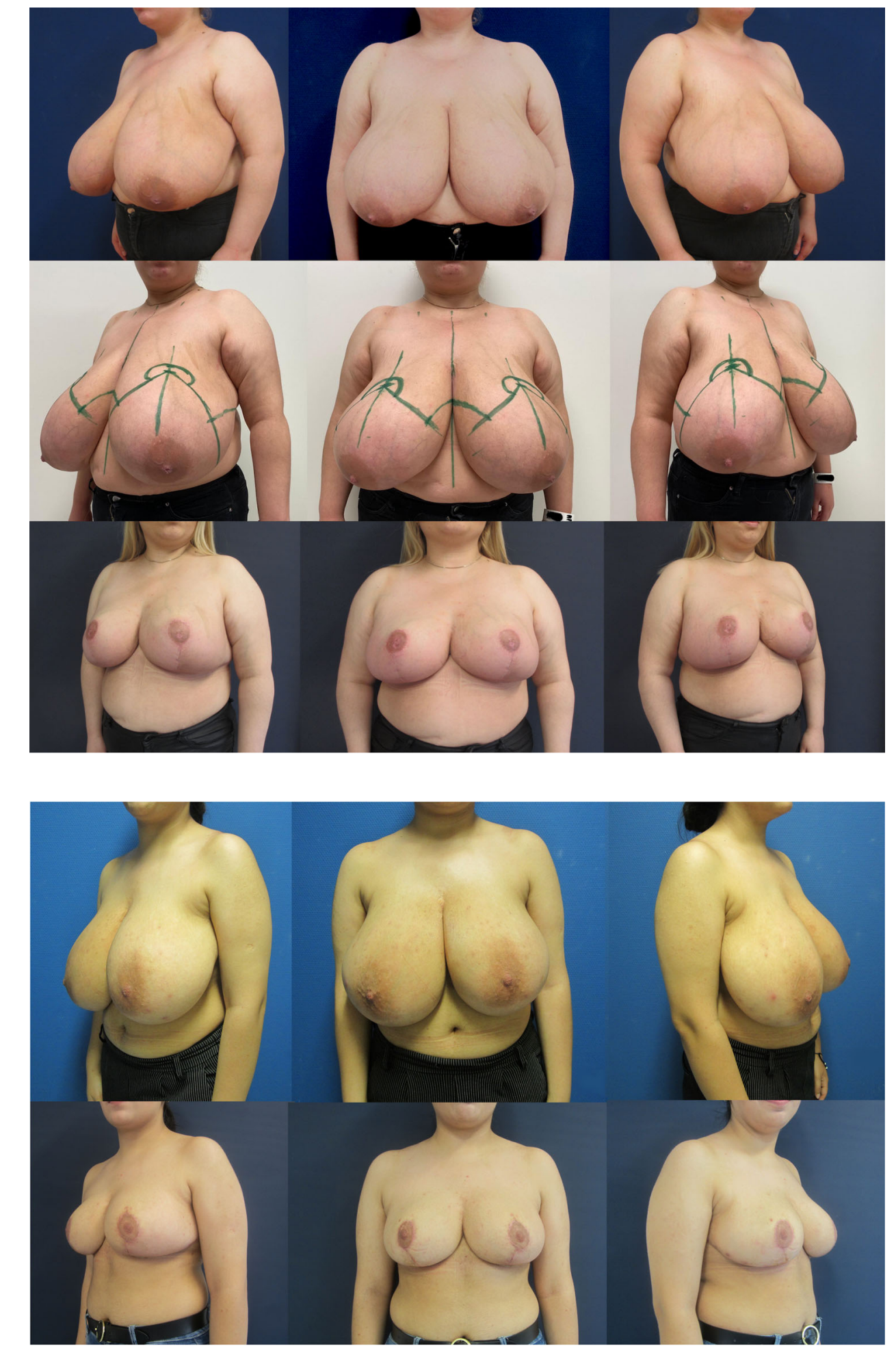

Fig. 9 Patient example 3. 20-year-old patient with cup size $75 \mathrm{G}, \mathrm{SN}-\mathrm{NAC}$ distance 36 $\mathrm{cm}$ right side and $34 \mathrm{~cm}$ left side, ptosis grade II by Regnault, BMI $26 \mathrm{~kg} / \mathrm{m}^{2}$.

Preoperative status (above), and 12 months postop (below) after Double-Unit SuperomedioCentral (DUS) Pedicled Inverted-T Reduction

Mammaplasty, form stable breast shape and good upper pole projection. Resection weight right side $\mathbf{1 6 0 2} \mathbf{g}$ and left side $1150 \mathrm{~g}$. (BMI: body mass index $\mathrm{kg} / \mathrm{m}^{2} ; \mathrm{SN}$ : sternal notch, NAC: nipple-areolar complex)
Recent publications still recommend a free NAC graft in severe gigantomastia cases $[16,41]$. We agree that free NAC grafting should generally be reserved for high-risk, older patients, when shorter operating times are paramount. Only a minority of publications analysed the results regarding NAC sensibility, secondary revisions and satisfaction with the aesthetic result. It is concluded that NAC sensibility was preserved by securing the robust and major neurovascular supply by the Superomedio-Central pedicle (83\% rated subjectively the sensibility as "high" and "medium"). The symmetry achieved with this method and consecutively the overall aesthetic outcome was rated 
Fig. 10 Patient example 4. 23-year-old patient with cup size $75 \mathrm{~K}$, SN-NAC distance 34 $\mathrm{cm}$ right side and $34 \mathrm{~cm}$ left side, ptosis grade II by Regnault, BMI $24 \mathrm{~kg} / \mathrm{m}^{2}$.

Preoperative status (above), and 18 months postop (below) after Double-Unit SuperomedioCentral (DUS) Pedicled

Inverted- $T$ Reduction

Mammaplasty, form

stable breast shape and good upper pole projection. Resection weight right side $1850 \mathrm{~g}$ and left side 1800 g. (BMI: body mass index $\mathrm{kg} / \mathrm{m}^{2} ; \mathrm{SN}$ : sternal notch, NAC: nipple-areolar complex)

Fig. 11 Patient example 5. 46-year-old patient with cup size $85 \mathrm{~N}$, SN-NAC distance 54 $\mathrm{cm}$ right side and $57 \mathrm{~cm}$ left side, ptosis grade III by Regnault, BMI $29 \mathrm{~kg} / \mathrm{m}^{2}$. Preoperative status (above), and 24 months postoperative (below) after free NAC graft and Double-Unit SuperomedioCentral (DUS) Pseudopedicled Inverted- $T$ Reduction

Mammaplasty, form

stable breast shape, good upper pole projection and mild NAC hypopigmentation. Resection weight right side $\mathbf{4 2 0 0} \mathbf{g}$ and left side $\mathbf{4 6 0 0}$ g. (BMI: body mass index $\mathrm{kg} / \mathrm{m}^{2}$; $\mathrm{SN}$ : sternal notch, NAC: nipple-areolar complex)
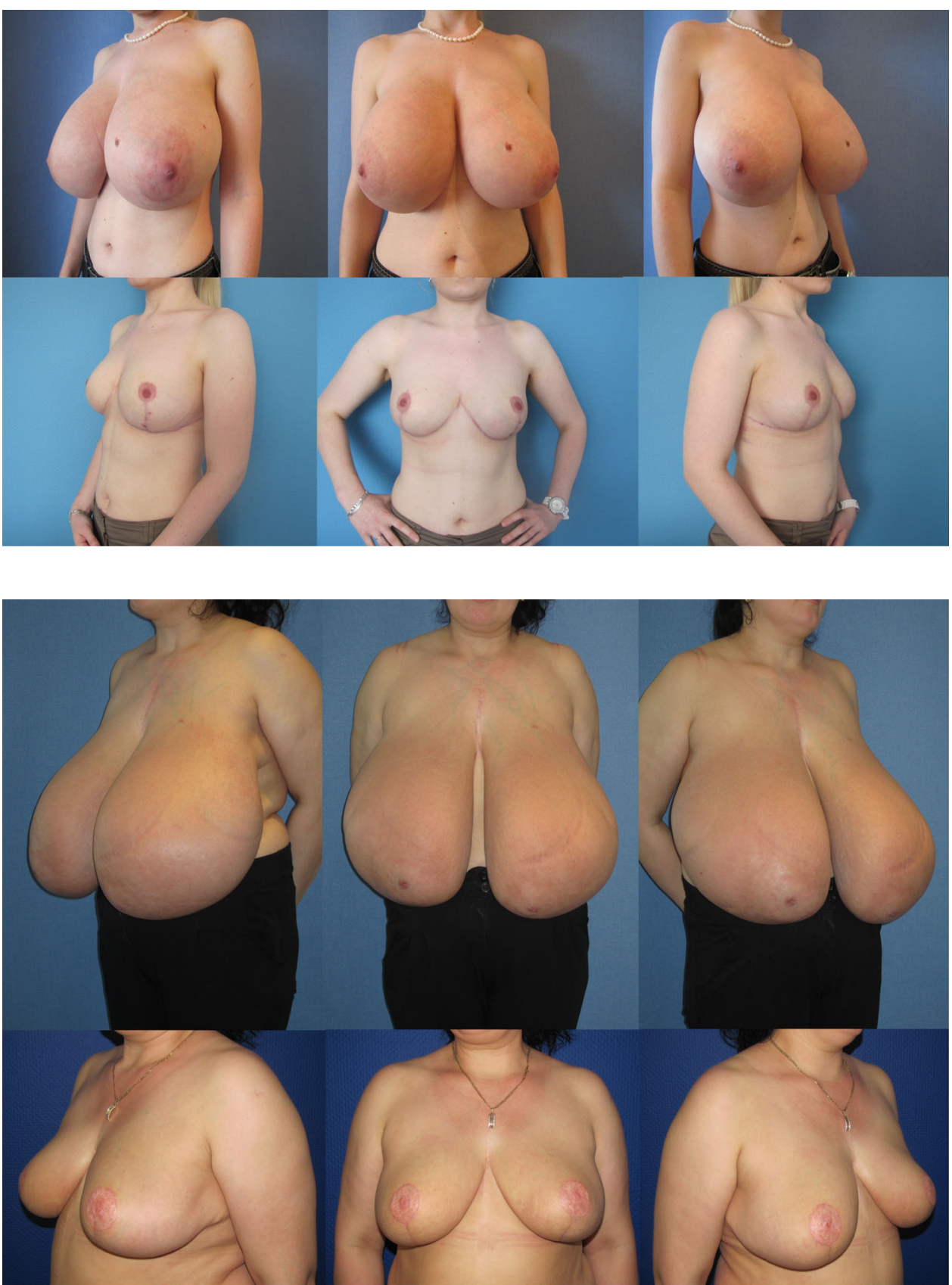
by the patients very high $(91 \%$ were "very satisfied" and "satisfied").

\section{Conclusion}

The Double-Unit Superomedio-Central (DUS) pedicled inverted- $T$ incision for reduction mammaplasty in gigantomastia is a reproducible and versatile technique. The preservation of the septum-based anterior intercostal artery perforators enhances the reliability of the neurovascular supply to the nipple-areolar complex. This modified procedure is very effective to achieve volume reduction and aesthetically pleasing reproducible results with a low complication rate in gigantomastic cases.

Funding Open Access funding enabled and organized by Projekt DEAL. None

\section{Declarations}

Conflict of interest The authors have no conflict of interest to disclose.

Human and Animal Rights This article does not contain any studies with human participants or animals performed by any of the authors.

Informed Consent All patients gave written consent for retrospective chart review and anonymous use of their photographs upon admission.

Ethical Approval All the procedures performed in this study that involved human participants were in accordance of the institutional, national research committee and with the 1964 Helsinki declaration and its later amendments or ethical standards.

Open Access This article is licensed under a Creative Commons Attribution 4.0 International License, which permits use, sharing, adaptation, distribution and reproduction in any medium or format, as long as you give appropriate credit to the original author(s) and the source, provide a link to the Creative Commons licence, and indicate if changes were made. The images or other third party material in this article are included in the article's Creative Commons licence, unless indicated otherwise in a credit line to the material. If material is not included in the article's Creative Commons licence and your intended use is not permitted by statutory regulation or exceeds the permitted use, you will need to obtain permission directly from the copyright holder. To view a copy of this licence, visit http://creativecommons. org/licenses/by/4.0/.

\section{References}

1. Dancey A, Khan M, Dawson J, Peart F (2008) Gigantomastia-a classification and review of the literature. J Plast Reconstr Aesthet Surg 61:493-502. https://doi.org/10.1016/j.bjps.2007.10.041

2. Mojallal A, Moutran M, Shipkov C et al (2010) Breast reduction in gigantomastia using the posterosuperior pedicle: an alternative technique, based on preservation of the anterior intercostal artery perforators. Plast Reconstr Surg 125:32-43. https://doi.org/10. 1097/PRS.0b013e3181c49561

3. Lugo LM, Prada M, Kohanzadeh S et al (2013) Surgical outcomes of gigantomastia breast reduction superomedial pedicle technique: a 12-year retrospective study. Ann Plast Surg 70:533-537. https://doi.org/10.1097/SAP.0b013e31827c7909

4. Landau AG, Hudson DA (2008) Choosing the superomedial pedicle for reduction mammaplasty in gigantomastia. Plast Reconstr Surg 121:735-739. https://doi.org/10.1097/01.prs. 0000299297.20908.66

5. Muslu Ü (2018) The evolution of breast reduction publications: a bibliometric analysis. Aesthet Plast Surg 42:679-691. https://doi. org/10.1007/s00266-018-1080-7

6. Popescu V (1989) Une methode personelle de resection dans la chirurgie de reductions mammaires. Rev Chir Esthet Langue Franc Tome XXII, Numero 72:23-30

7. Karacor-Altuntas Z, Dadaci M, Ince B et al (2016) Central pedicle reduction in gigantomastia without free nipple graft. Ann Plast Surg 76:383-387. https://doi.org/10.1097/SAP. 0000000000000388

8. Karacaoglu E, Zienowicz RJ (2017) Septum-inferior-medial (SIM)-based pedicle: a safe pedicle with well-preserved nipple sensation for reduction in gigantomastia. Aesthet Plast Surg. https://doi.org/10.1007/s00266-016-0763-1

9. Kemaloğlu CA, Özocak H (2018) Comparative outcomes of inferior pedicle and superomedial pedicle technique with wise pattern reduction in gigantomastic patients. Ann Plast Surg 80:217-222. https://doi.org/10.1097/SAP.0000000000001231

10. Azzam C, De Mey A (2007) Vertical scar mammaplasty in gigantomastia: retrospective study of 115 patients treated using the modified Lejour technique. Aesthetic Plast Surg 31:294-298. https://doi.org/10.1007/s00266-006-0227-0

11. Portincasa A, Ciancio F, Cagiano L et al (2017) Septum-enhanced mammaplasty in inferocentral pedicled breast reduction for macromastia and gigantomastia patients. Aesthet Plast Surg 41:1037-1044. https://doi.org/10.1007/s00266-017-0868-1

12. Popescu V (1996) Ma strategie d'aujourd'hui dans les reductions mammaires et les mastopexies. Rev Chir Esthet Langue Franc Tome XXI, Numero 84:31-42

13. Greco R, Noone B (2017) Evidence-based medicine: reduction mammaplasty. Plast Reconstr Surg 139:230e-239e. https://doi. org/10.1097/PRS.0000000000002856

14. Bauermeister AJ, Gill K, Zuriarrain A et al (2019) Reduction mammaplasty with superomedial pedicle technique: a literature review and retrospective analysis of 938 consecutive breast reductions. J Plast Reconstr Aesthet Surg 72:410-418. https://doi. org/10.1016/j.bjps.2018.12.004

15. Basaran K, Saydam FA, Ersin I et al (2014) The free-nipple breast-reduction technique performed with transfer of the nippleAreola complex over the superior or superomedial pedicles. Aesthetic Plast Surg 38:718-726. https://doi.org/10.1007/s00266014-0343-1

16. Karsidag S, Akcal A, Karsidag T et al (2011) Reduction mammaplasty using the free-nipple-graft vertical technique for severe breast hypertrophy: improved outcomes with the superior dermaglandular flap. Aesthet Plast Surg 35:254-261. https://doi.org/ 10.1007/s00266-010-9592-9

17. Orlando JC, Guthrie RH (1975) The superomedial dermal pedicle for nipple transposition. Br J Plast Surg 28:42-45. https://doi.org/ 10.1016/S0007-1226(75)90149-6

18. Lejour M (1994) Vertical mammaplasty and liposuction of the breast. Plast Reconstr Surg 94:100-114. https://doi.org/10.1097/ 00006534-199407000-00010

19. Hall-Findlay EJ (1999) A simplified vertical reduction mammaplasty: shortening the learning curve. Plast Reconstr Surg 
104:748-759. https://doi.org/10.1097/00006534-19990901000020

20. HallFindlay EJ (2004) Vertical breast reduction. Semin Plast Surg 18:211-224. https://doi.org/10.1055/s-2004-831908

21. Hall-Findlay EJ, Shestak KC (2015) Breast reduction. Plast Reconstr Surg 136:531e-544e. https://doi.org/10.1097/PRS. 0000000000001622

22. Yuksel F, Karagoz H, Sever C, Kulahci Y (2012) Experience with vertical mammaplasty: advantages and drawbacks of HallFindlay's superomedial pedicle technique and improving the results by adding modifications to the technique. Aesthet Plast Surg 36:1329-1333. https://doi.org/10.1007/s00266-012-9979-x

23. Serra MP, Longhi P, Sinha M (2010) Breast reduction with a superomedial pedicle and a vertical scar (Hall-Findlay's technique): experience with 210 consecutive patients. Ann Plast Surg 64:275-278. https://doi.org/10.1097/SAP.0b013e3181b0a611

24. Michelle le Roux C, Kiil BJ, Pan WR et al (2010) Preserving the neurovascular supply in the Hall-Findlay superomedial pedicle breast reduction: an anatomical study. J Plast Reconstr Aesthetic Surg 63:655-662. https://doi.org/10.1016/j.bjps.2009.01.014

25. Hall-Findlay EJ (2011) Aesthetic breast surgery: concepts \& technique. In: Aesthetic breast surgery: concepts \& technique, quality medical publishing, Inc., St. Louis, Missouri, Chapter 6: 261

26. Würinger E, Mader N, Posch E, Holle J (1998) Nerve and vessel supplying ligamentous suspension of the mammary gland. Plast Reconstr Surg 101:1486-1493. https://doi.org/10.1097/ 00006534-199805000-00009

27. Kling RE, Tobler WD, Gusenoff JA, Rubin JP (2016) Avoiding complications in gigantomastia. Clin Plast Surg 43:429-439. https://doi.org/10.1016/j.cps.2015.12.006

28. Rohrich RJ, Gosman AA, Brown SA et al (2004) Current preferences for breast reduction techniques: a survey of board-certified plastic surgeons 2002. Plast Reconstr Surg 114:1724-1733. https://doi.org/10.1097/01.prs.0000142480.27748.9e

29. Van Deventer PV, Graewe FR (2016) The blood supply of the breast revisited. Plast Reconstr Surg 137:1388-1397. https://doi. org/10.1097/PRS.0000000000002048

30. Palmer JH, Ian Taylor G (1986) The vascular territories of the anterior chest wall. Br J Plast Surg 39:287-299. https://doi.org/ 10.1016/0007-1226(86)90037-8

31. Spear SL, Howard MA (2003) Evolution of the vertical reduction mammaplasty. Plast Reconstr Surg 112:855-868

32. Hammond DC, O'Connor EA, Knoll GM (2015) The short-scar periareolar inferior pedicle reduction technique in severe mammary hypertrophy. Plast Reconstr Surg 135:34-40

33. Davison SP, Mesbahi AN, Ducic I et al (2007) The versatility of the superomedial pedicle with various skin reduction patterns. Plast Reconstr Surg 120:1466-1476. https://doi.org/10.1097/01. prs.0000282033.58509.76

34. Antony AK, Yegiyants SS, Danielson KK et al (2013) A matched cohort study of superomedial pedicle vertical scar breast reduction (100 breasts) and traditional inferior pedicle wise-pattern reduction (100 breasts): an outcomes study over 3 years. Plast Reconstr Surg 132:1068-1076

35. Hester TR, Bostwick J, Miller L, Cunningham SJ (1985) Breast reduction utilizing the maximally vascularized central breast pedicle. Plast Reconstr Surg 76:890-898
36. Würinger E (1999) Refinement of the central pedicle breast reduction by application of the ligamentous suspension. Plast Reconstr Surg 103:1400-1410. https://doi.org/10.1097/ 00006534-199904050-00008

37. Bucaria V, Elia R, Maruccia M et al (2018) Why choose the septum-supero-medial (SSM)-based mammaplasty in patients with severe breast ptosis: an anatomical point of view. Aesthet Plast Surg 42:1439-1446. https://doi.org/10.1007/s00266-0181189-8

38. Pallua N, Kim BS, Mon O'Dey D (2020) The short scar threeblock L-wing technique. J Plast Reconstr Aesthet Surg 73:1075-1080. https://doi.org/10.1016/j.bjps.2020.01.027

39. Simpson AM, Donato DP, Kwok AC, Agarwal JP (2019) Predictors of complications following breast reduction surgery: a national surgical quality improvement program study of 16,812 cases. J Plast Reconstr Aesthet Surg 72:43-51. https://doi.org/10. 1016/j.bjps.2018.09.002

40. Nahabedian MY, McGibbon BM, Manson PN (2000) Medical pedicle reduction mammaplasty for severe mammary hypertrophy. Plast Reconstr Surg 105:896-904. https://doi.org/10.1097/ 00006534-200003000-00011

41. Misirlioglu A, Akoz T (2005) Familial severe gigantomastia and reduction with the free nipple graft vertical mammoplasty technique: report of two cases. Aesthet Plast Surg 29:205-209. https://doi.org/10.1007/s00266-004-0134-1

42. Lacerna M, Spears J, Mitra A, et al (2005) Avoiding free nipple grafts during reduction mammaplasty in patients with gigantomastia. Ann Plast Surg 55:21-24

43. Roehl K, Craig ES, Gómez V, Phillips LG (2008) Breast reduction: safe in the morbidly obese? Plast Reconstr Surg 122:370-378. https://doi.org/10.1097/PRS.0b013e31817d60f4

44. Amini P, Stasch T, Theodorou P, et al (2010) Vertical reduction mammaplasty combined with a superomedial pedicle in gigantomastia. Ann Plast Surg 64:279-285. https://doi.org/10.1097/ SAP.0b013e3181b0a5d8

45. Ulusal BG, Alper I (2018) In pursuit of effective volume reduction and enhanced aesthetics for treatment of gigantomastia using superior dermoglandular pedicle. Aesthetic Plast Surg 42:412-421. https://doi.org/10.1007/s00266-017-1067-9

46. Elmelegy NG, Sadaka MS, Hegazy AM, Abdeldaim DE (2018) Treatment of gigantomastia using a medial-lateral bipedicle reduction mammoplasty: the role of doppler-assisted preoperative perforator identification. Aesthetic Plast Surg 42:73-79. https:// doi.org/10.1007/s00266-017-1049-y

47. Wolter A, Pluto N, Scholz T, et al (2017) [Ribeiro-technique in gigantomastia - review of 294 reduction mammaplasties in 8 years]. Handchir Mikrochir Plast Chir 49:390-398. https://doi. org/10.1055/s-0043-113132

48. Thorek M (1989) Possibilities in the reconstruction of the human form. Aesthet Plast Surg 13:55-58. https://doi.org/10.1007/ BF01570326

Publisher's Note Springer Nature remains neutral with regard to jurisdictional claims in published maps and institutional affiliations. 